\title{
How does exercising make you feel? The associations between positive and negative affect, life satisfaction, self-esteem, and vitality
}

Filipe Rodrigues, Tânia Faustino, Abel Santos, Eduardo Teixeira, Luís Cid \& D. Monteiro

To cite this article: Filipe Rodrigues, Tânia Faustino, Abel Santos, Eduardo Teixeira, Luís Cid \& D. Monteiro (2021): How does exercising make you feel? The associations between positive and negative affect, life satisfaction, self-esteem, and vitality, International Journal of Sport and Exercise Psychology, DOI: 10.1080/1612197X.2021.1907766

To link to this article: https://doi.org/10.1080/1612197X.2021.1907766

Published online: 29 Mar 2021.

Submit your article to this journal $₫$

View related articles

View Crossmark data \lceil 


\title{
How does exercising make you feel? The associations between positive and negative affect, life satisfaction, self-esteem, and vitality
}

\author{
Filipe Rodrigues (1D ${ }^{a, b}$, Tânia Faustino ${ }^{a}$, Abel Santos ${ }^{a, b}$, Eduardo Teixeira ${ }^{a, b}$, \\ Luís Cid (D) ${ }^{\mathrm{a}, \mathrm{c}}$ and D. Monteiro ${ }^{\mathrm{c}, \mathrm{d}}$ \\ ${ }^{a}$ Sport Science School of Rio Maior (ESDRM - IPSantarém), Rio Maior, Portugal; ${ }^{\mathrm{b}}$ Life Quality Research Center

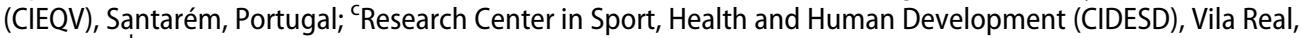 \\ Portugal; ${ }^{d}$ ESECS, Polytechnic of Leiria, Leiria, Portugal
}

\begin{abstract}
The purpose of this study was to examine the relationship between regular physical exercise and affective responses to the behaviour, and to investigate the relationship with life satisfaction, self-esteem, and vitality. In total, 264 Portuguese exercisers (female $=157$ ) aged between 18 and 69 years $(M=12.93 ; S D=1.49)$ were considered for analysis in this study. Participants were regular exercisers with a mean year experience of $5.73(S D=3.19)$. Looking at the results, the structural model displayed acceptable fit to the data: $X^{2}(314)$ $=515.904 ; p<.001 ; \mathrm{CFI}=.928 ; \mathrm{TLI}=.919 ;$ RMSEA .049 [.042, .057]. Overall, significant direct effects were found as theoretically proposed, namely: exercise frequency displayed a positive and significant association with positive affect; positive affect was positively associated with life satisfaction, self-esteem, and subjective vitality; and, negative affect was negatively correlated with life satisfaction, self-esteem, and subjective vitality. Exercise frequency had a positive and significant indirect effect on life satisfaction, self-esteem, and subjective vitality via positive affect, but not via negative affect.
\end{abstract}

\section{ARTICLE HISTORY}

Received 9 September 2020

Accepted 4 March 2021

\section{KEYWORDS}

Exercise; affects; life satisfaction; self-esteem; subjective vitality

\section{Introduction}

It is well established in the literature that engagement in regular physical activity comes with physical and mental benefits (Warburton \& Bredin, 2019). While a large amount of research has focused on the physiological aspect of exercise and its relationship with non-communicable diseases (Lee et al., 2012) and performance (e.g., academic achievement; Barbosa et al., 2020), there are still some gaps in the literature related to its association with psychological aspects such as well-being and other adaptive outcomes linked to the self. While motivation has been pointed out as a major contributor to physical activity participation, Ekkekakis and Dafermos (2012) have questioned the usefulness of motivational and cognitive models in explaining this behaviour. Their research showed that social-cognitive models typically only account for approximately $25 \%$ of the variance in exercise and physical activity behaviour, which limits the creation of effective 
interventions in reversing trends of physical inactivity. As an alternative, exercise could be better understood by considering the affective components associated with physical activity behaviour. Existing literature (Teixeira et al., 2018a, 2018b) has explored the influence of regular exercise to better understand the affective response, while other outcomes such as subjective vitality and self-esteem are still under-researched in the context of interest.

Our primary goal in this study is to explore the possibility that cognitive self-worth processes and well-being mechanisms have, in part, an affective basis (Ekkekakis \& Dafermos, 2012) considering the engagement in regular physical activity. Specifically, we hypothesise that individuals engaged in exercise at health and fitness centres experience adaptive outcomes such as feelings of energy, well-being, and overall optimal self-concept, in which positive and negative affect could play a mediation role.

\section{Positive and negative affect: conceptualisation and the influence of physical activity}

Positive affect refers to the extent to which an individual subjectively experiences positive moods such as pride, interest, and happiness (Watson et al., 1988). While positive emotions and positive affect seem to be overlap in some degree, they are not identical (Ekkekakis, 2012). Although the former involves positive feelings as well as characteristic patterns of physiological arousal, the latter is conceptualised as mood states (Peterson, 2006). High positive affect is characterised as a state of high energy, full concentration, and pleasurable engagement, whereas low positive affect is characterised by sadness and lethargy (Schmukle et al., 2012). On the other hand, negative affect is related to negative expression and mood states, which includes fear, sadness, disgust, and distress (Watson et al., 1988). High negative affect is a general dimension of subjective distress that subsumes a variety of negative mood states, while low negative affect is conceptualised as being a state of calmness and serenity (Schmukle et al., 2012).

In general, being currently physically active has been associated with more positive affective experiences (Barnett, 2013). In a study conducted by Hogan et al. (2013), considering 144 participants of ages ranging from 19 to 93 years, assigned to a control group or to a moderate-intensity exercise group, researchers found that physical activity increased high-arousal positive affect in the intervention group but not in the control group. Contrarily, higher physical activity participation displayed a negative association with negative affect. Previous studies have demonstrated that the greater level of physical activity was related to lower stress levels as well as with negative affect (Schultchen et al., 2019). Hence, there is some evidence that positive and negative affect are related to the degree of exercising (Teixeira et al., 2018b).

While these studies found a robust association between physical activity and affective responses to the behaviour, the consequences of positive and negative affect are still under-researched in the exercise context. In fact, there is scarcity on the assessment of affect and its relationship with well-being (Teixeira et al., 2018a). We propose to explore three components related to the self, such as self-esteem, life satisfaction, and vitality. These psychological outcomes were assessed because they are generally regarded as adaptive, healthy, and crucial indicators of well-being (Diener et al., 2017). 
As such, self-esteem, life satisfaction, and vitality appear to capture part of the "brighter side" that may help individuals feel well about themselves.

\section{Correlates of positive and negative affects: self-esteem, life satisfaction, and vitality}

Research on self-esteem has long held that the sense of self is largely constructed through interaction with and feedback from significant others (Coffrey \& Warren, 2020). According to Rosenberg (1965), self-esteem is conceptualised as a sense of self-worth that is based on simply being who one is, rather than on attaining success or certain results. The state of self-esteem seems to be related to affective responses. The more frequently people experience positive affect, the more opportunities they have on building a positive image towards the self. Recent findings indicate that the tendency to emphasise positive affective states is associated with higher levels of self-esteem (Benetti \& Kambouropoulos, 2006; Liu et al., 2014). Hence, individuals with greater feeling of self-worth may feel this way due to an increase in positive affect and a decrease in negative affect. Contrarily, some authors (Liu et al., 2014; Yildirim et al., 2019) showed that individuals high on negative affect are particularly susceptible to threats to self-esteem.

The variable of vitality is also evaluated within the study areas of positive psychology like self-esteem. Subjective vitality is conceptualised as the state of feeling alive and having energy available to the self (Ryan \& Deci, 2001). Much of the impetus for examining the correlates of positive/negative affect comes from the association of positive wellbeing with health, and the research literature showing that psychological well-being is related to better health is growing (Ekkekakis et al., 2020). There is evidence that positive affect is associated with greater experience of subjective vitality (Couto et al., 2017). Contrarily, negative affect might reflect pessimism or doubts that efforts to improve one's health will provide adaptive outcomes. Thus, it should be theorised that negative affect would have a negative relationship with subjective vitality, since being in a negative mood influences the judgment towards living to be more negative (Ryan \& Deci, 2017).

Another important aspect of well-being is life satisfaction. Research in the past years has made considerable progress in identifying the factors that influence people's subjective well-being all around the world (Diener et al., 1985; Kuppens et al., 2008; Kushlev et al., 2020). Scholars have distinguished two components of well-being: cognitive one related to the evaluation of the satisfaction with one's life as a whole, and an affective judgement that refers to positive and negative emotionality (Kuppens et al., 2008), which is going to be examined in this research, as we intend to examine the relationship of positive and negative affect, and life satisfaction. Regarding the relation between positive and negative affect and life satisfaction, literature has shown that when people make affective judgments about life satisfaction, mood states serve as an important source of information (Schimmack et al., 2002). Related to this, experimental studies have shown that positive and negative experiences have a causal influence on satisfaction (Schwarz \& Clore, 1983), that is, positive affect positively predicted life satisfaction, while negative affect had a negative effect. Overall, people with high levels of positive affect deal more effectively with mood states and achieve a greater sense of life satisfaction. On the other hand, higher experience of negative affect is negatively associated with life satisfaction (Yamasaki et al., 2011; Ye \& Lin, 2015). 
While the association between affect and well-being indicators seems to be theoretically robust, cited studies have been conducted in non-physical-activity contexts (e.g., Coffrey \& Warren, 2020; Liu et al., 2014). In fact, to the best of our knowledge, few studies have examined the relationship between physical activity, affect, and how individuals feel about themselves. It is possible that additional insight into this relationship could be achieved by examining the association between regular physical activity and the affective response to this behaviour.

\section{Current research}

There is some evidence (e.g., Liu et al., 2015) that physical activity interventions are beneficial to increase the self-esteem of children and adolescents. Hence, we theorise that positive and negative affect could play a mediation role in this association in individuals engaged in regular exercise. Teixeira et al. (2018b) found that positive affect was not, but negative affect was, significantly related to psychological distress and fatigue in a sample of hundred and fifty-five exercisers. On the other hand, positive affect (but not negative affect) was significantly associated with well-being. It is worth to mention that Teixeira et al. (2018b) explored the predictive role of motivational determinants, grounded on self-determination theory, on affect and well-being, meaning that the impact of physical activity is still yet to be examined.

The underlying logic of examining positive outcomes of the affective response towards regular exercise is that low engagement in physical activity tends to generate low selfworth (Liu et al., 2014; Monteiro et al., 2021) and greater risk factor depression (Warburton \& Bredin, 2019). Researchers have also proposed mechanisms by which physical activity and affect could lead to improved mental health (Magnan et al. 2013), meaning that high positive affect and low negative affect are associated with greater levels of adaptive outcomes.

A significant contribution of this study is the acknowledgement about the specificity of exercise in a context of health and fitness centres. While exercisers are assumed to engage regular physical activity mostly for self-determined reasons and motives (Rodrigues et al., 2020), we could assume that being active is important to them and that this could explain mostly greater experience of positive affect and less negative affect. The present study expands the area of affective responses to exercise research and complements previous literature (Ekkekakis et al., 2020) by investigating how exercisers' positive and negative affect could be associated with indicators of well-being like life satisfaction, selfesteem, and subjective vitality. This knowledge may guide fitness instructors in their intervention during training sessions making them aware of the importance of the affect fostered in their fitness classes. Thus, results would provide guidance on how to manipulate physical activity as a means to promote vitality, self-esteem, and life satisfaction, based on the positive and negative affects experienced during exercise (Teixeira \& Palmeira, 2016).

The purpose of this study was to examine the relationship between regular exercise and affective response to the behaviour, and to investigate the relationship with life satisfaction, self-esteem, and vitality in the context of health and fitness centres. Considering previous research, we hypothesised that relatively more-active (higher exercise frequency) versus less-active (lower exercise frequency) exercisers will experience more positive affect (Magnan et al., 2013). In turn, we also speculate that positive affect would have 
a positive relationship with life satisfaction, self-esteem, and vitality (Couto et al., 2017; Ryan \& Deci, 2017). On the other hand, higher engagement in regular physical activity would have a negative relationship with negative affect (Niermann et al., 2016), which ultimately is negatively associated with previously reported outcomes (Ryan \& Deci, 2017; Ye \& Lin, 2015).

\section{Methods}

\section{Participants}

In total, 264 Portuguese exercisers (female $=157$ ) aged between 18 and 69 years $(M=$ 12.93; $S D=1.49$ ) were considered for analysis in this study. Participants were regular exercisers (mean year experience $=5.73 ; \mathrm{SD}=3.19$ ) from several health and fitness centres in Portugal. For inclusion, potential participants we considered those who met the following inclusion criteria: (i) age 18 or older; (ii) provided informed consent to participate; and (iii) had more than six months of regular exercise practice.

\section{Measures}

For measuring exercise frequency, participants were asked to report their weekly frequency over the last months, using the following question: "How many days do you think you have exercised over the last week?".

Exercisers completed the short version of the Positive and Negative Affect Schedule (PANAS) Portuguese version (Galinha et al., 2014) to measure the experience of positive (5 items: e.g., "inspired") and negative (5 items: e.g., "nervous") affect. This version contains ten items, preceded by the stem "To what extent do you feel each of the emotions when training" in which participants responded to each item using a 5-point scale ranging from 1 ("totally disagree") to 5 ("totally agree"). According to Mackinnon et al. (1999), the PANAS 10-item version can be recommended for use when measures of positive and negative affect are studied.

The Subjective Vitality Scale Portuguese version (Moutão et al., 2013) was used to measure subjective vitality using six items (e.g., "Sometimes I feel so alive I just want to burst"). Responses were provided to each item by indicating the degree to which the statement was true in general in their life, using a 7-point scale anchored from 1 ("not true at all") and 7 ("very true"). The original scale had 7 items and was validated by Ryan and Frederick (1997). Subsequent work by Bostic et al., (2000) using confirmatory factor analyses indicated that a 6-item version worked better than the 7-item version.

The Rosenberg Self-esteem scale Portuguese version (Faria \& Silva, 2000) was used to measure self-esteem. While the original version contains ten items, we considered only those positively coded (5 items: e.g., "I feel that I have a number of good qualities") since reverse coded items can contaminate results (Sonderen et al., 2013). Study participants indicated how strongly they agree or disagree with each statement using a 4-point Likert scale format ranging from 1 ("strongly agree") to 4 ("strongly disagree"). This scale is the most widely used measure of self-esteem for research purposes and has provided adequate model fit (Baumeister et al., 2003) and the factor has displayed an acceptable score of internal consistency (Rosenberg, 1965). 
The Satisfaction with Life Scale Portuguese version (Neto, 1993) was used to measure satisfaction with life. This 5 -item scale is designed to measure global cognitive judgments of one's life satisfaction, and study participants responded to each item using a 7-point scale ranging from 1 ("totally disagree") to 7 ("strongly agree"). This scale has shown to be a valid and reliable measure of life satisfaction, suited for use with a wide range of age groups and empirical applications (Pavot et al., 1991).

\section{Procedures}

Data collection procedures were conducted in accordance with the 1964 Helsinki declaration and its later amendments or comparable ethical standards. Ethical approval was obtained by the Ethical Committee before data collection. Following ethical institutional approval (omitted for review) a health centre by convenience was contacted. Objectives and data collection procedures were explained individually to the health centre manager. After approval, potential participants were contacted at the reception desk prior to a training session and were asked to participate voluntarily in this study. Participants who agreed to participate completed the online survey prior to a training session using Google form. Mean time to complete the survey was approximately $18 \min (S D=2.13)$. Exercisers received no compensation for participating in this study but were thanked for their contribution.

\section{Statistical analysis}

Descriptive statistics as well as latent correlations were calculated for each variable. Cutoffs for normality were considered based on guidelines accepting scores within -2/ +2 and $-7 /+7$ for skewness and kurtosis, respectively (Gravetter \& Wallnau, 2014). Composite reliability (CR) coefficients were calculated considering coefficients above 0.70 as acceptable (Raykov, 1997). Associations were examined using bivariate correlations.

Afterwards, a two-step analysis proposed by Kline (2016) was followed. First a confirmatory factor analysis and then a structural equation model considering all variables under analysis was performed. For model fit, several traditional and incremental indexes were considered, namely: Comparative Fit Index (CFI), Tucker-Lewis Index (TLI), Root Mean Square Error of Approximation (RMSEA) and its respective 90\% Confidence Interval (C190\%). Scores of CFI and TLI $\geq 0.90$, and RMSEA $\leq 0.80$ were indicative of acceptable fit, as proposed by several authors (Byrne, 2011; Hair et al., 2019). The chi-square test $\left(X^{2}\right)$ and the degrees of freedom will be reported for visualisation purposes but not examined, as they are both affected by the complexity of the model and sample size (Hair et al., 2019).

Direct and indirect effects were analyzed according to standardised coefficients and their respective 95\% Confidence Interval (C195\%). Regression paths were considered significant if the C195\% did not include zero (Williams \& Mackinnon, 2008).

\section{Results}

\section{Preliminary analysis}

Mean for positive affect was higher compared to negative affect. Means for life satisfaction, self-esteem, and subjective vitality were above midpoint as seen in Table 1. 
Table 1. Descriptive statistics, composite reliability coefficients, and latent correlations.

\begin{tabular}{|c|c|c|c|c|c|c|c|c|c|c|}
\hline Variables & $M$ & SD & $S$ & $\mathrm{~K}$ & $C R$ & 1 & 2 & 3 & 4 & 5 \\
\hline 1. Exercise Frequency & 3.01 & 1.26 & .71 & 1.79 & - & - & & & & \\
\hline 2. Positive Affect & 3.47 & .77 & -.54 & .45 & .89 & $.13^{*}$ & - & & & \\
\hline 3. Negative Affect & 1.62 & .75 & 1.60 & 2.32 & .85 & -.08 & $-.33^{* *}$ & - & & \\
\hline 4. Life Satisfaction & 3.59 & .65 & -.37 & .79 & .80 & .09 & $.45^{* *}$ & $-.31^{* *}$ & - & \\
\hline 5. Self-Esteem & 4.95 & .83 & -.87 & .27 & .73 & .10 & $.73^{* *}$ & $-.49^{* *}$ & $.58^{* *}$ & - \\
\hline 6. Subjective Vitality & 3.98 & .20 & -.89 & 1.32 & .87 & $.24^{* *}$ & $.73^{* *}$ & $-.35^{* *}$ & $.44^{* *}$ & $.76^{* *}$ \\
\hline
\end{tabular}

Notes: $\mathrm{M}=$ Mean; $\mathrm{SD}=$ Standard Deviation; $\mathrm{S}=$ Skewness; $\mathrm{K}=$ Kurtosis; $\mathrm{CR}=$ Composite Reliability coefficients. ${ }^{*} p<0.05 ;{ }^{* *} p<0.01$.

Skewness and kurtosis were contained within cutoffs, showing normal distribution. In addition, composite reliability coefficients were above adequate showing acceptable internal consistency (>0.70). Looking at the latent correlations: (a) exercise frequency displayed asignificant association with positive affect and subjective vitality; (b) positive affect showed a positive significant relationship with all variables, except negative affect which displayed a negative association; (c) negative affect displayed a negative association with life satisfaction, self-esteem, and subjective vitality; and, (d) all outcomes were positively and significantly correlated with each other. For more information see Table 1.

The measurement model provided acceptable fit to the data: $\chi^{2}(310)=468.879 ; p$ $<.001 ; \mathrm{CFI}=.943 ; \mathrm{TLI}=.936$; RMSEA .044 [.036, .052]. Considering these results of the measurement model, and the acceptable composite reliability coefficients, we move forward on testing the structural model. Looking at the results, the structural model displayed acceptable fit to the data: $X^{2}(314)=515.904 ; p<.001 ; \mathrm{CFI}=.928 ; \mathrm{TLI}=.919 ; \mathrm{RMSEA}$ $.049[.042, .057]$. Hence, direct and indirect paths were analyzed.

Overall, significant direct effects were found as theoretically proposed, namely: (a) exercise frequency displayed a positive and significant association with positive affect; (b) positive affect was positively associated with life satisfaction, self-esteem, and subjective vitality; and, (c) negative affect was negatively correlated with life satisfaction, selfesteem, and subjective vitality. In Figure 1 are displayed direct and total indirect effects between variables.

Regarding indirect effects, several results emerged. Exercise frequency had a positive and significant indirect effect with life satisfaction, self-esteem, and subjective vitality via positive affect, but not via negative affect (see Table 2). Nonetheless, the total indirect effect from exercise frequency to each dependent variable was positive and significant (see dashed lines in Figure 1).

\section{Discussion}

There has been a dearth of empirical research examining the association between physical activity and affective response that underlie well-being indicators. The aim of the present study was to take some steps towards addressing this gap by examining a hypothesised model whereby regular exercise is related to positive and negative affect that are disparately related to life satisfaction, self-esteem, and vitality of gym and fitness centre exercisers. In accordance with our hypothesis, the results indicated that exercise frequency was significantly and positively related with positive affect, and 
$8 \Leftrightarrow$ F. RODRIGUES ET AL.

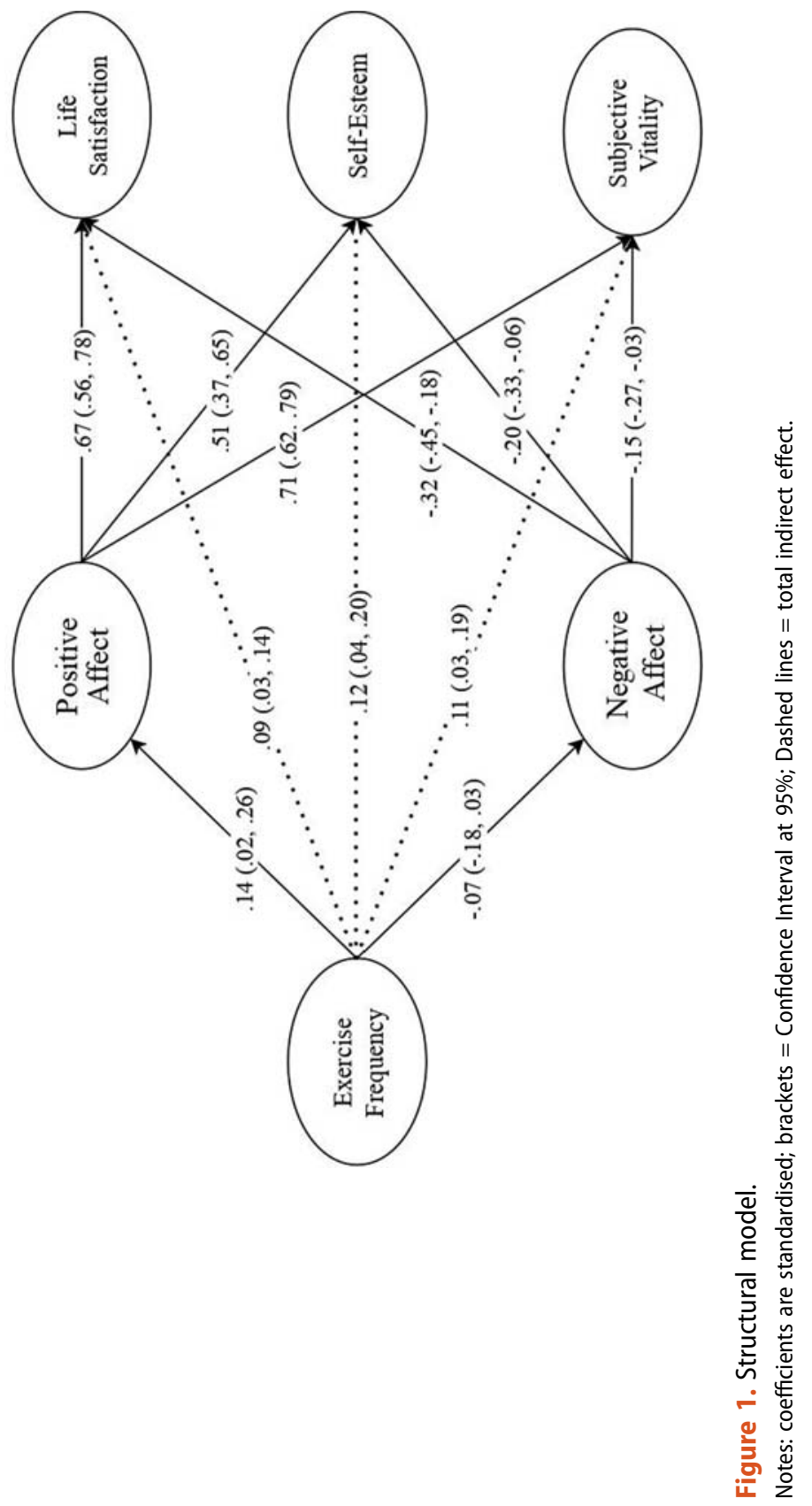


Table 2. Indirect effect coefficients.

\begin{tabular}{llrrr}
\hline & & & & IC95\% \\
\cline { 2 - 4 } & \multicolumn{1}{c}{ LB } & UB \\
\hline Exercise Frequency $\rightarrow$ Positive Affect $\rightarrow$ Life Satisfaction & .07 & .03 & .02 & .12 \\
Exercise Frequency $\rightarrow$ Negative Affect $\rightarrow$ Life Satisfaction & .02 & .01 & -.03 & .04 \\
Exercise Frequency $\rightarrow$ Positive Affect $\rightarrow$ Self-Esteem & .09 & .04 & .02 & .16 \\
Exercise Frequency $\rightarrow$ Negative Affect $\rightarrow$ Self-Esteem & .02 & .02 & -.01 & .05 \\
Exercise Frequency $\rightarrow$ Positive Affect $\rightarrow$ Subjective Vitality & .10 & .05 & .02 & .17 \\
Exercise Frequency $\rightarrow$ Negative Affect $\rightarrow$ Subjective Vitality & .01 & .01 & -.01 & .03
\end{tabular}

Notes: $\beta=$ standardised regression coefficient; $\mathrm{SE}=$ Standardized Error; C195\% $=95 \%$ Confidence Internal; $\mathrm{LB}=\mathrm{Lower}$ Bound; UB = Upper Bound.

negatively with negative affect. Consequently, positive affect was significantly related to life satisfaction, self-esteem, and subjective vitality, while negative displayed a negative association. Additionally, exercise frequency exerted a significant positive indirect effect on all three outcomes via positive affect.

\section{Exercise and affect}

In the proposed model, exercise frequency was positively associated with positive affect, but not with negative affect. It seems that for exercisers, to feel higher levels of positive affect, they need to exercise regularly. These results are somewhat comparable to those reported by Magnan et al. (2013), where regular physical activity and affective response to exercise are positively related. While individual affective response seems to translate in the quality and quantity of physical activity (Ekkekakis et al., 2020), current results show that exercise frequency can indicate the positive affect exercisers have during fitness activities in health and fitness centres. Hence, exercisers who engage in regular physical activity within the health and fitness context will also show greater positive affect towards the activity itself. Regarding the non-significant association between exercise frequency and negative affect could be explained by the context. The fact that it is a "choice" to do the activity would seem to provide some evidence that exercisers do not feel or experience negative affect during the activity. Thus, fitness instructs should foster and endorse regular physical activity as a means for exercisers to experience pleasurable (e.g., feeling of enjoyment, excitement, enthusiasm) rather than unpleasurable (e.g., ashamed, nervous) affective states.

It is worth to mention that the assessment of affect was done prior to a training session. Specifically, we asked exercisers to report how they feel during exercise on a regular basis prior. Thus, this decision could have influenced current results, since intensity and duration influence the affective state (Ekkekakis et al., 2020). The assessment of affect prior, during, and after a training session should be considered in forthcoming studies.

\section{Affect and well-being indicators}

In path analysis, positive affect was positively, while negative affect was negatively associated with life satisfaction in a sample of regular exercisers. The present findings suggest that for exercisers life satisfaction could also be added to the list of adaptive processes that are associated with positive affect in the health and fitness context. Such optimal 
functioning may lead to general well-being (Diener, 2017) that is associated with a wide range of positive behavioural and psychological outcomes (see Proctor et al. 2018). While previous nation-wide studies have demonstrated considerable differences on the emphasis placed on positive and negative experiences in life satisfaction judgment (Kuppen et al., 2008), our results support their claims specifically related to Portugal, where individuals high on positive affect also display higher scores on satisfaction with life. While the study conducted by Kuppen and colleagues (2008) was conducted at the general level, it is worth to mention the preliminary evidence of current results in the exercise context. Hence, it seems that positive affect at the contextual level can have a significant association with life satisfaction at the general level.

Current results also show that only positive affect was positively and significantly related to self-esteem, thereby supporting the role of positive affect in experiencing adaptive outcomes (Ekkekakis et al., 2020). Thus, a more frequent self-attribution of positive affective state during physical exercise displays greater sense of self-esteem. This pattern of results supports the argument that affective states are particularly important in regulating levels of self-esteem during activities that individuals enjoy engaging (Liu et al., 2014). Thus, exercisers with a favourable attitude towards themselves are more likely to reinforce their positive affect to keep that positive self-conception.

Concerning subjective vitality, higher positive affect showed a significant association with subjective vitality, while negative affect displayed a negative and significant relationship in the same outcome. These findings suggest that individuals who are physically active, besides lowering their risk of premature death or chronic disease and physical disability (Warburton \& Bredin, 2019) should experience a sense of psychological well-being, based on the experience of positive affect during the activity. Thus, there is evidence that exercising at the health and fitness centre can promote well-being at the general level, supporting the assumptions that the feeling of pleasure in a specific context can have implications at the global level on exercisers (Evmenenko \& Teixeira, 2020). This study fills a gap in the literature related to the measurement of vitality in the exercise context, showing consistent results with previous studies in other domains (Ryan \& Frederick, 1997).

\section{Mediating role of affect}

Although previous studies (e.g., Teixeira et al., 2018b) have shown that motivation mediates the effects of needs on several outcomes such as positive and negative affect and well-being, this study is the first to show that positive affect could serve the same function in individuals engaged in health and fitness activities. First, analyses reveal that the proposed model fits the data well. Thus, it suggests that positive affect could play a mediation role between exercise frequency and well-being indicators. Specifically, individuals' exercise frequency was found to positively predict positive affect, which in turn was related to life satisfaction, self-esteem, and subjective vitality. These findings suggest that exercisers who choose to exercise regularly, experience adaptive affective states, thus resulting in greater perceptions of well-being in general. Thus, positive affect experienced during the exercise by individuals in the context of health and fitness could contribute to an overall optimal functioning at the general level (Teixeira et al., 2018a). In this regard, the feeling of energy available 
to the self and the sense of enthusiasm and aliveness is contingent on the positive state exerciser experience during the fitness activity. Thus, fitness professionals should interact with exerciser in a manner that they feel positive affective responses towards exercising. While the manipulation of affective states is yet to be explored in the exercise context, current results shed some preliminary insights on how this association between affect and self-esteem could be possible, due to the quantity (and quality) of physical exercise.

\section{Strengths, limitations, and agenda for future research}

A strength of our study is the focus on robust statistical tests and theoretical models considering an under-researched context of regular gym and health club exercisers. Consequently, this work has provided evidence of the affective response towards exercise and its association between adaptive outcomes (i.e., more self-esteem, life satisfaction, and subjective vitality). The present research is a preliminary look into the mechanisms by which exercise behaviour may translate into a more positive and subjective experience of exercise, ultimately translating into well-being and self-esteem. Replication and extension of current results using additional potential mediators such as basic psychological needs, behavioural regulation, and objectively measured outcomes (e.g., exercise participation using attendance records) is warranted to better elucidate the mechanisms underlying this relationship.

There were some limitations in this study that should be considered. First, participants were regular exercisers from a convenience sample of health and fitness centres. Relatedly, this study was conducted in Portugal, thus results cannot be generalised to other cultures and contexts. Second, we did not control for exercise intensity and duration, as it seems to be significantly related to the affective response to exercise (Ekkekakis et al., 2020). In this regard, the critical issue of the timing of assessments of affect should be considered in future studies. Third, the cross-sectional design used in this study should be explored by longitudinal or prospective designs so that causal relations can be tested. Another limitation is the consideration of only adaptive outcomes. While the objective was to investigate the association between exercise, affect, and well-being indicators, future studies should also consider the predictive role of affect on maladaptive outcomes (e.g., burnout, psychological distress, fatigue) in the health and fitness context. Last, while this study did not measure the fitness activities exercisers where engaged in, forthcoming studies could assess and examine possible differences between gym and health club activities such as more relaxed (e.g., pilates) compared to more energetic and intense ones (e.g., Crosstraining, pump).

\section{Practical implications}

The current study takes some steps towards helping to further knowledge on the affective processes that underlie both exercising and the experience of vitality, life satisfaction, and self-esteem in the setting of health and fitness centres. Our results are consistent with the premise that exercising can be used, and likely is used, as a way to promote well-being indicators, based on the positive affect exercisers have during a training session, which 
was supported with our indirect effects. To the extent that exercising behaviour on the long term is mainly driven by self-determined regulations (Rodrigues et al., 2020), fitness instructors could make changes to their interpersonal behaviours and communication styles that are focused on the attainment of adaptive outcomes at the contextual (e.g., energised towards fitness activities) and general (e.g., overall well-being and selfesteem towards life) level.

\section{Conclusion}

Regular physical activity seems to be inherently related to affective response towards exercising participation. Consequently, positive affect is positively associated with the feeling of life satisfaction, self-esteem, and subjective vitality, while negative affect shows a negative association with these three outcomes in the context of exercise. Understanding affect from a contextual perspective provides a broader view of the relationship between exercise and affect. Although affect is understood to be a complex phenomenon, exercise frequency seems to be an important determinant of the affective response individuals report during physical exercise. Selecting an appropriate exercise schedule could induce a more pleasurable affective experience and assist in the consistent adherence to exercise programmes, as well as on the promotion of general well-being experience, life satisfaction, and self-esteem.

Additionally, the findings suggest that the influence of exercise on life satisfaction, self-esteem, and vitality may be mediated by the levels of affect. Importantly, it seems that exercise acts as an important factor by increasing feelings of positive affect which in turn may bolster self-esteem and indicators of well-being. Thus, empirical evidence is offered to support the belief that exercisers generally feel better about themselves and that their regular participation may be an important factor in maintaining positive affect and consequently heightened life satisfaction, self-esteem, and subjective vitality.

\section{Acknowledgements}

Filipe Rodrigues was supported by the national funds through the Portuguese Foundation for Science and Technology, I.P., under the project UID/04748/2020. Luís Cid and Diogo Monteiro were supported by national funds through the Portuguese Foundation for Science and Technology, I.P., under the project UID04045/2020.

\section{Disclosure statement}

No potential conflict of interest was reported by the author(s).

\section{Funding}

Filipe Rodrigues was supported by the national funds through the Portuguese Foundation for Science and Technology, I.P., under the project UIDP/04748/2020. Luís Cid and Diogo Monteiro were supported by national funds through the Portuguese Foundation for Science and Technology, I.P., under the project UID04045/2020. 


\section{ORCID}

Filipe Rodrigues (i) http://orcid.org/0000-0003-1327-8872

Luís Cid (iD http://orcid.org/0000-0001-8156-3291

\section{References}

Barbosa, A., Whiting, S., Simmonds, P., Moreno, R., Mendes, R., \& Breda, J. (2020). Physical activity and academic achievement: An umbrella review. International Journal of Environmental Research and Public Health, 17(16), e5972. https://doi.org/10.3390/ijerph17165972

Barnett, F. (2013). The effect of exercise on affective and self-efficacy responses in older and younger women. Journal of Physical Activity and Health, 10(1), 97-105. https://doi.org/10.1123/jpah.10.1.97

Baumeister, R., Campbell, J., Krueger, J., \& Vohs, K. (2003). Does high self-esteem cause better performance, interpersonal success, happiness, or healthier lifestyles? Psychological Science in the Public Interest, 4(1), 1-44. https://doi.org/10.1111/1529-1006.01431

Benetti, C., \& Kambouropoulos, N. (2006). Affect-regulated indirect effects of trait anxiety and trait resilience on self-esteem. Personality and Individual Differences, 41(2), 341-352. https://doi.org/10. 1016/j.paid.2006.01.015

Byrne, B. (2011). Structural equation modeling with mplus: Basic concepts, applications, and programming. Routledge.

Coffey, J., \& Warren, M. (2020). Comparing adolescent positive affect and self-esteem as precursors to adult self-esteem and life satisfaction. Motivation and Emotion, 44, 707-718. https://doi.org/ 10.1007/s11031-020-09825-7

Couto, N., Antunes, R., Monteiro, D., Moutão, J., Marinho, D., \& Cid, L. (2017). Impact of the basic psychological needs in subjective happiness. Subjective Vitality and Physical Activity in an Elderly Portuguese Population. Motricidade, 13(2), 58-70. https://doi.org/10.6063/motricidade. 9746

Diener, E., Emmons, R., Larsen, R., \& Griffin, S. (1985). The satisfaction with life scale. Journal of Personality Assessment, 49(1), 71-75. https://doi.org/10.1207/s15327752jpa4901_13

Diener, E., Pressman, S., Hunter, J., \& Delgadillo-Chase, D. (2017). If, why, and when subjective wellbeing influences health, and future needed research. Applied Psychology: Health and Well-Being, 9 (2), 133-167. https://doi.org/10.1111/aphw.12090

Ekkekakis, P. (2012). Affect, mood, and emotion. In G. Tenenbaum, R. Eklund, \& A. Kamata (Eds.), Measurement in sport and exercise psychology (pp. 321-332). Human Kinetics.

Ekkekakis, P., \& Dafermos, M. (2012). Exercise is a many-splendored thing, but for some it does not feel so splendid: Staging a resurgence of hedonistic ideas in the quest to understand exercise behavior. In P. Nathan \& E. Acevedo (Eds.), The Oxford handbook of exercise psychology (pp. 295-333). Oxford: Oxford University Press.

Ekkekakis, P., Hartman, M., Ladwig, M., Tenenbaum, G., Eklund, R., \& Boiangin, N. (2020). Affective responses to exercise. In G. Tenenbaum, \& R. Eklund (Eds.), Handbook of sport psychology (4th ed., pp. 231-253). John Wiley \& Sons, Inc. https://doi.org/10.1002/9781119568124.ch12

Evmenenko, A., \& Teixeira, D. (2020). The circumplex model of affect in physical activity contexts: a systematic review. International Journal of Sport and Exercise Psychology. https://doi.org/10. 1080/1612197X.2020.1854818

Faria, L., \& Silva, S. (2000). Efeitos do exercício físico na promoção do autoconceito. Psychologica, 25, $25-43$.

Galinha, I., Pereira, C., \& Esteves, F. (2014). Versão reduzida da escala portuguesa de afeto positivo e negativo - PANAS-VRP: Análise fatorial confirmatória e invariância temporal. Psicologia, 28(1), 5365. https://doi.org/10.17575/rpsicol.v28i1.622

Gravetter, F., \& Wallnau, L. (2014). Essentials of statistics for the behavioral sciences (8th ed.). Cengage Learning.

Hair, J., Black, W., Babin, B., \& Anderson, R. (2019). Multivariate data analysis (8th ed). Pearson Educational, Inc. 
Hogan, C., Mata, J., \& Carstensen, L. (2013). Exercise holds immediate benefits for affect and cognition in younger and older adults. Psychology and Aging, 28(2), 587-594. https://doi.org/10.1037/ a0032634

Kline, R. (2016). Principles and practice of structural equation modelling (3rd ed). Guilford Press.

Kuppens, P., Realo, A., \& Diener, E. (2008). The role of positive and negative emotions in life satisfaction judgment across nations. Journal of Personality and Social Psychology, 95(1), 66-75. https:// doi.org/10.1037/0022-3514.95.1.66

Kushlev, K., Drummond, D., \& Diener, E. (2020). Subjective well-being and health behaviors in 2.5 million Americans. Applied Psychology: Health and Well-Being, 12(1), 166-187. https://doi.org/ 10.1111/aphw.12178

Lee, I., Shiroma, E., Lobelo, F., Puska, P., Blair, S., Katzmarzyk, P., \& Lancet Physical Activity Series Working Group. (2012). Effect of physical inactivity on major non-communicable diseases worldwide: An analysis of burden of disease and life expectancy. The Lancet, 380(9838), 219-229. https://doi.org/10.1016/S0140-6736(12)61031-9

Liu, Y., Wang, Z., Zhou, C., \& Li, T. (2014). Affect and self-esteem as mediators between trait resilience and psychological adjustment. Personality and Individual Differences, 66, 92-97. https://doi.org/ 10.1016/j.paid.2014.03.023

Liu, M., Wu, L., \& Ming, Q. (2015). How does physical activity intervention improve self-esteem and self-concept in children and adolescents? Evidence from a meta-analysis. PloS One, 10(8), e0134804. https://doi.org/10.1371/journal.pone.0134804

Mackinnon, A., Jorm, A., Christensen, H., Korten, A., Jacomb, P., \& Rodgers, B. (1999). A short form of the positive and negative affect schedule: Evaluation of factorial validity and invariance across demographic variables in a community sample. Personality and Individual Differences, 27(3), 405-416. https://doi.org/10.1016/S0191-8869(98)00251-7

Magnan, R., Kwan, B., \& Bryan, A. (2013). Effects of current physical activity on affective response to exercise: Physical and social-cognitive mechanisms. Psychology and Health, 28(4), 418-433. https://doi.org/10.1080/08870446.2012.733704

Monteiro, D., Rodrigues, F., \& Lopes, V. (2021). Social support provided by the best friend and vigorous-intensity physical activity in the relationship between perceived benefits and global selfworth of adolescents. Revista de Psicodidática, 26(1), 70-77. https://doi.org/10.1016/j.psicod. 2020.11.004

Moutão, J., Alves, S., \& Cid, L. (2013). Translation and validation of the subjective vitality scale in a Portuguese sample of exercise participants. Revista Latinoamericana de Psicologia, 45(2), 223230. https://doi.org/10.14349/rlp.v45i2.842

Neto, F. (1993). The satisfaction with life scale: Psychometrics properties in an adolescent sample. Journal of Youth and Adolescence, 22(2), 125-134. https://doi.org/10.1007/BF01536648

Niermann, C., Herrmann, C., Haaren, B., Kann, D., \& Woll, A. (2016). Affect and subsequent physical activity: An ambulatory assessment study examining the affect-activity association in a real-life context. Frontiers in Psychology, 7, Article 677. https://doi.org/10.3389/fpsyg.2016.00677

Pavot, W., Diener, E., Colvin, C., \& Sandvik, E. (1991). Further validation of the satisfaction with life scale: evidence for the cross-method convergence of wellbeing measures. Journal of Personality Assessment, 57(1), 149-161. https://doi.org/10.1207/s15327752jpa5701_17

Peterson, C. (2006). A primer in positive psychology. Oxford University Press.

Proctor, C., Alex Linley, P., \& Maltby, P. (2018). Life Satisfaction. In R.J.R. Levesque . (Ed.), Encyclopedia of Adolescence. Cham: Springer. https://doi.org/10.1007/978-3-319-33228-4_125

Raykov, T. (1997). Estimation of composite reliability for congeneric measures. Applied Psychological Measurement, 21(2), 173-184. https://doi.org/10.1177/01466216970212006

Rodrigues, F., Teixeira, D., Neiva, H., Cid, L., \& Monteiro, D. (2020). Understanding exercise adherence: The predictability of past experience and motivational determinants. Brain Sciences, 10(2), 98. https://doi.org/10.3390/brainsci10020098

Rosenberg, M. (1965). Society and the adolescent self-image. Princeton University Press.

Ryan, R., \& Deci, E. (2017). Self-Determination theory: Basic psychological needs in motivation, development, and wellness. Guilford. ISBN: 9781462538966. 
Ryan, R. M., \& Deci, E. L. (2001). To be happy or to be self-fulfilled: A review of research on hedonic and eudaimonic well-being. In S. Fiske (Ed.), Annual Review of Psychology (Vol. 52, pp. 141-166). Palo Alto, CA: Annual Reviews, Inc.

Ryan, R., \& Frederick, C. (1997). On energy, personality, and health: Subjective vitality as a dynamic reflection of well-being. Journal of Personality, 65(3), 529-565. https://doi.org/10.1111/j.14676494.1997.tb00326.x

Schimmack, U., Oishi, S., \& Diener, E. (2002). Cultural influences on the relation between pleasant emotions and unpleasant emotions: Asian dialectic philosophies or individualism-collectivism? Cognition and Emotion, 16(6), 705-719. https://doi.org/10.1080/02699930143000590

Schmukle, S., Egloff, B., \& Burns, L. (2012). The relationship between positive and negative affect in the positive and negative affect schedule. Journal of Research in Personality, 36(5), 463-475. https://doi.org/10.1016/S0092-6566(02)00007-7

Schultchen, D., Reichenberger, J., Mittl, T., Weh, T., Smyth, J. M., \& Blechert, J. (2019). Bidirectional relationship of stress and affect with physical activity and healthy eating. British Journal of Health Psychology, 24(2), 315-333. https://doi.org/10.1111/bjhp.12355

Schwarz, N., \& Clore, G. (1983). Mood, misattribution, and judgments of well-being: Informative and directive functions of affective states. Journal of Personality and Social Psychology, 45(3), 513-523. https://doi.org/10.1037/0022-3514.45.3.513

Sonderen, E., Sanderman, R., \& Coyne, J. (2013). Ineffectiveness of reverse wording of questionnaire items: let's learn from cows in the rain. PloS one, 8(7), e68967. https://doi.org/10.1371/journal. pone.0068967

Teixeira, D., Marques, M., \& Palmeira, A. (2018a). Associations between affect, basic psychological needs and motivation in physical activity contexts: Systematic review and meta-analysis. Revista Iberoamericana de Psicologia del Ejercicio y el Deporte, 13(2), 225-233.

Teixeira, D., \& Palmeira, A. (2016). Needs satisfaction effect on exercise emotional response: A serial mediation analysis with motivational regulations and exercise intensity. Motriz: Revista de Educação Física, 22(4), 368-375. https://doi.org/10.1590/s1980-6574201600040023

Teixeira, D., Silva, M., \& Palmeira, A. (2018b). How does frustration make you feel? A motivational analysis in exercise context. Motivation and Emotion, 42(3), 419-428. https://doi.org/10.1007/ s11031-018-9690-6

Warburton, D., \& Bredin, S. (2019). Health benefits of physical activity: A strengths-based approach. Journal of Clinical Medicine, 8(12), Article 2044. https://doi.org/10.3390/jcm8122044

Watson, D., Clark, L. A., \& Tellegen, A. (1988). Development and validation of brief measures of positive and negative affect: The PANAS scales. Journal of Personality and Social Psychology, 54(6), Article 1063. https://doi.org/10.1037/0022-3514.54.6.1063

Williams, J., \& Mackinnon, D. (2008). Resampling and distribution of the product methods for testing indirect effects in complex models. Structural Equation Modeling: A Multidisciplinary Journal, 15(1), 23-51. https://doi.org/10.1080/10705510701758166

Yamasaki, K., Sasaki, M., Uchida, K., \& Katsuma, L. (2011). Effects of positive and negative affect and emotional suppression on short-term life satisfaction. Psychology, Health and Medicine, 16(3), 313-322. https://doi.org/10.1080/13548506.2011.554564

Ye, Y., \& Lin, L. (2015). Examining relations between locus of control, loneliness, subjective wellbeing, and preference for online social interaction. Psychological Reports, 116(1), 164-175. https://doi.org/10.2466/07.09.PR0.116k14w3

Yildirim, M., Alshehri, N., \& Aziz, I. (2019). Does self-esteem mediate the relationship between gratitude and subjective well-being? Polish Psychological Bulletin, 50(2), 149-156. https://doi.org/10. 24425/ppb.2019.126030 